\title{
Into the night: camera traps reveal nocturnal activity in a presumptive diurnal primate, Rhinopithecus brelichi
}

\author{
Chia L. Tan $\cdot$ Yeqin Yang $\cdot$ Kefeng Niu
}

Received: 31 May 2012/ Accepted: 12 July 2012/Published online: 29 July 2012

(C) The Author(s) 2012. This article is published with open access at Springerlink.com

\begin{abstract}
Most living primates exhibit a daytime or nighttime activity pattern. Strict diurnality is thought to be the rule among anthropoids except for owl monkeys. Here we report the diel activity pattern of an Asian colobine, the Guizhou snub-nosed monkey Rhinopithecus brelichi, based on a methodology that relied on using 24-h continuously operating camera traps. We conducted the study in Fanjingshan National Nature Reserve in Guizhou, China from March 22 to May 19 and from June 17 to October 14, 2011. After standardizing all time elements to a meridian-based time according to the geographic coordinates of the study site, we showed unequivocally that the monkeys, though predominantly diurnal, exhibited activity beyond daylight hours throughout the study. Specifically, their activity at night and during twilight periods suggests a complex interplay of behavioral adaptations, among others, to living in a temperate environment where day length and food resources fluctuate substantially across seasons. We contend that, under prevailing ecological conditions, so-called strictly diurnal primates may adjust their activity schedule opportunistically in order to increase energy intake. We also discuss the advantages of using camera traps in primate studies, and how the standardized use of meridianbased time by researchers would benefit comparisons of diel activity patterns among primates.
\end{abstract}

\footnotetext{
C. L. Tan $(\bowtie)$
}

San Diego Zoo Institute for Conservation Research,

San Diego Zoo Global, 15600 San Pasqual Valley Road,

Escondido, CA92027, USA

e-mail: ctan@sandiegozoo.org

Y. Yang $\cdot$ K. Niu

Fanjingshan National Nature Reserve Administration,

Tongren 554400, Guizhou, People's Republic of China
Keywords Camera traps - Rhinopithecus brelichi . Diel activity pattern $\cdot$ Nocturnality $\cdot$ Fanjingshan

\section{Introduction}

Camera traps have become an effective tool for studies of wildlife populations without direct observation or physically capturing animals. Use of camera traps is particularly ideal for surveying elusive animals in vast, remote areas with difficult field conditions that prohibit adequate sampling using more traditional methodologies (Kays and Slauson 2008; O'Connell et al. 2011). Beyond population surveys and monitoring, camera traps are useful in ecological and behavioral research, as images captured may reveal key information about habitat, and the behavior of species on an individual as well as group basis (Bridges and Noss 2011). Because most primate species are not cryptic, direct observation by researchers has proven to be generally effective, with behavioral data often being collected over prolonged periods of time especially following habituation of animals. Thus, camera traps appeared to offer limited applications in primate behavioral studies (e.g., Blake et al. 2010; Pebsworth et al. 2011).

Free-ranging Chinese snub-nosed monkeys (Rhinopithecus spp.) present huge field challenges for researchers. Elusive and difficult to track, these monkeys form supertroops of 100-400 individuals that traverse mountainous terrain, covering large home ranges that often exceed $20 \mathrm{~km}^{2}$ (Kirkpatrick et al. 1998; Tan et al. 2007; Grueter et al. 2008; Niu et al. 2010). We applied camera trap technology to our research on free-ranging Guizhou snubnosed monkeys $R$. brelich $i$ - an endangered species with a single global population of 700-800 individuals restricted to Fanjingshan in southwest China (Yang et al. 2002). The 
intent was to reduce the knowledge gaps impeded by brief contact time with the monkeys through direct observation. Specifically, in this study we focused on the diel (24-h) activity pattern of $R$. brelichi. Camera traps offered the advantage of uninterrupted monitoring, while minimizing disturbance caused by human observers, and eliminating the need for habituation that potentially could lead to increased poaching.

On the basis of known habits, morphological features, and phylogenetic affinity, R. brelichi is assumed to be exclusively diurnal (e.g., Bleisch and Xie 1998; see Kay and Kirk 2000, Table 1; Yang et al. 2002; Niu et al. 2010). Here we report our camera-trap results from an initial six-month investigation. We address the ecological implications of the observed activity pattern, and discuss the significance of our findings in conjunction with methodological improvements needed for studying this and other presumptive solely diurnal species.

\section{Methods}

This study was conducted in Fanjingshan National Nature Reserve (FNNR) in northeast Guizhou Province, China $\left(27^{\circ} 49^{\prime}-28^{\circ} 01^{\prime} \mathrm{N}, 108^{\circ} 45^{\prime}-48^{\prime} \mathrm{E}\right)$. FNNR contains 41,900 ha of subtropical and temperate forests with major vegetation zones graded according to elevations: evergreen broadleaf forest $(<1,300 \mathrm{~m})$, mixed evergreen and deciduous broadleaf forest (1,300-2,200 m), and mixed deciduous broadleaf, conifer, and scrub forest $(>2,200 \mathrm{~m})$ (Yang et al. 2002). The climate is seasonally distinct. Snow and freezing rain are common in winter and early spring. In 2010-2011, the mean monthly temperatures varied from $-4.4{ }^{\circ} \mathrm{C}$ (January) to $21.9^{\circ} \mathrm{C}$ (July), and the annual precipitation was $1,606 \mathrm{~mm}$ (using Onset ${ }^{\circledR}$ Hobo U30/NRC Weather Station, Tan et al. unpubl. data from $1,300 \mathrm{~m}$ elevation). Fanjingshan is the only refuge for the focal species, $R$. brelichi. Another nonhuman primate, the Tibetan macaque Macaca thibetana, occurs sympatrically.

As part of a reserve-wide, biodiversity survey and an indepth study of $R$. brelichi, we deployed 40 remote digital cameras with passive infrared sensors (i.e., camera traps) in Yangaoping, located in the northeast parcel of FNNR. Yangaoping, ranging from 800 to $>2,000 \mathrm{~m}$ in elevation, constitutes the core habitat of $R$. brelichi (Bleisch and Xie 1998; Yang et al. 2002; see Niu et al. 2010, Fig. 1 for map). Details regarding the digital images reported here are from two camera traps, LT003 and LT004, set approximately $10 \mathrm{~m}$ apart in an area dominated by beech trees Fagus lucida $\left(27^{\circ} 57^{\prime} 09.8-10.3^{\prime \prime} \mathrm{N}, 108^{\circ} 45^{\prime} 22.4-24.3^{\prime \prime} \mathrm{E}\right.$, elevation $1,650 \mathrm{~m}$ ). The cameras (Bushnell ${ }^{\circledR}$ Trophy
$\mathrm{Cam}^{\mathrm{TM}}$ XLT119435c), each equipped with a 2-gigabyte Secure Digital (class 2) memory card and 8 extended-use AA batteries, were mounted below the canopy at 5-6 m above ground level. Before operating, we adjusted the infrared sensor to normal, the capture setting to the multiimage mode of 3 images per trigger, and the time lapse between triggers to 10 -s intervals. We also programmed the date and time according to China Standard Time (CST). The cameras operated continuously throughout the 24-h cycle from March 22 to May 19 and from June 17 to October 14, 2011, totaling 294 trap days.

Images captured by the two camera traps were cataloged separately, then classified by species, date, and time. We evaluated whether or not an image series (in multiples of three) constituted an independent event by adopting the definition outlined by O'Brien et al. (2003) with minor modifications. Specifically, we defined an independent event as a (1) successive image series of different individuals of the same or different species, (2) successive image series of individuals of the same species captured $>1 \mathrm{~h}$ apart, or (3) nonsuccessive image series of individuals of the same species. Because the two camera traps were deployed in the same general area, any image series of a species from the two cameras with overlapping date and time were treated as a single event.

We subsequently assigned an activity period to each independent event based on its time of occurrence. Using the definitions of the Astronomical Applications Department of the United States Naval Observatory (USNO) (http://aa.usno.navy.mil) regarding the rising and setting of the sun, we categorized the activity period of each event as:

- $\quad$ Twilight $=$ occurring during periods of civil twilight (i.e., when the sun is $0-6^{\circ}$ below the horizon) either before sunrise or after sunset;

- Daytime (or diurnal) = occurring during the period between sunrise and sunset; or

- $\quad$ Nighttime (or nocturnal) = occurring during the period after civil twilight ends in the evening and before civil twilight begins the next morning.

From the USNO website, we also obtained the precise times of sunrise/set and civil twilight begin/end calculated to the longitude and latitude coordinates of our camera trap location, and a meridian time of $+7.24 \mathrm{~h}$ east of Greenwich Mean Time (GMT) (given our location is approximately $4^{\circ} \mathrm{E}$ of $\mathrm{GMT}+7 \mathrm{~h}$; central meridian $\left.105^{\circ} \mathrm{E}\right)$. Because our camera traps were originally set to CST (i.e., GMT $+8 \mathrm{~h}$; central meridian $120^{\circ} \mathrm{E}$ ), we then corrected the times of independent events by subtracting 44 min from the image time stamps. Astronomical information regarding the moon was similarly gathered using the USNO data services. 

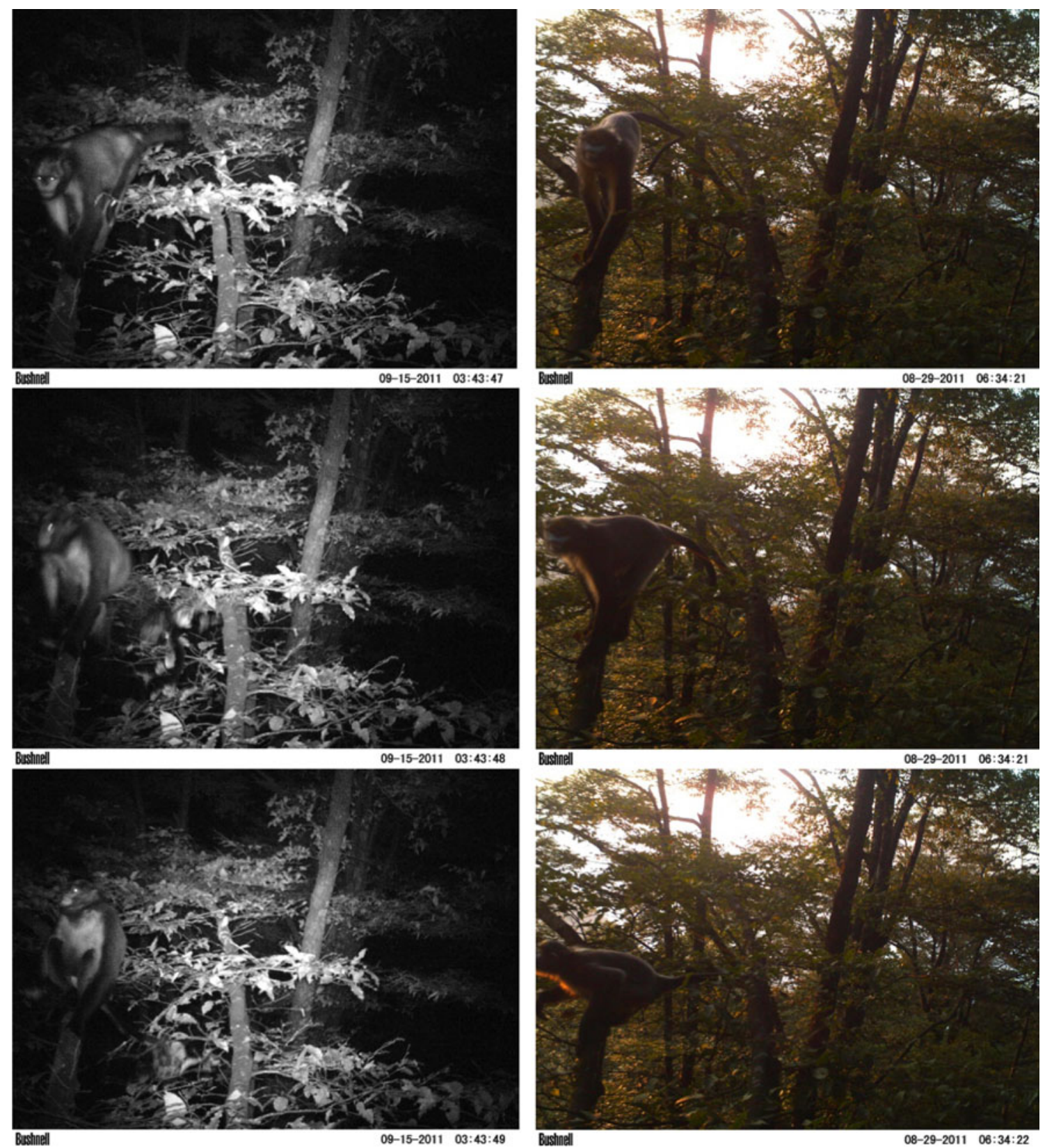

Fig. 1 A comparison of nocturnal (left column) versus diurnal (right column) images captured by camera trap LT004 showing R. brelichi individuals moving through the beech forest (note: image time stamps reflect CST before correction; see "Methods")

\section{Results}

Images of four vertebrate species were captured by our camera traps; they included those of $R$. brelichi, M. thibetana, the giant flying squirrel Petaurista sp., and the golden pheasant Chrysolophus pictus. From the images, we ascertained 24 independent events of our focal species that occurred on 21 days from April through October (except May) (Table 1). These events involved R. brelichi individuals of all age and sex classes, and they showed the monkeys active during different periods of the diel cycle.
In particular, diurnal activity accounted for 18 of the 24 events $(75 \%)$, which were concentrated in early morning (i.e., from the beginning of civil twilight to ca. $30 \mathrm{~min}$ after sunrise) and late afternoon (i.e., from ca. $30 \mathrm{~min}$ before sunset to the end of civil twilight). The remaining six events $(25 \%)$ were considered nocturnal, and all but one (September 15, see below) appeared to be extensions of activity schedule beyond the periods of civil twilight. The monkeys' activity events after sunset and before sunrise did not consistently correspond to the fraction of the moon illuminated. Moreover, based on the temporal distribution 
Table 1 Date and time of independent events $(n=24)$ involving $R$. brelichi captured by two camera traps and the category of activity period as defined by the corresponding time of sunrise or sunset. All times are adjusted to reflect a meridian time base $\left(\mathrm{E} 108^{\circ} 45^{\prime}, \mathrm{N}\right.$ $27^{\circ} 57^{\prime},+7.24$ h east of GMT). See "Methods" for details

\begin{tabular}{|c|c|c|c|c|}
\hline Date & Event time (h) & Activity period & Sunrise/set time ${ }^{\mathrm{a}}(\mathrm{h})$ & Moon fraction ${ }^{\mathrm{a}}(\%)$ \\
\hline $04 / 22 / 11$ & $1824-1833$ & Day $\rightarrow$ twilight & $0528 / 1828$ & 0 , below horizon \\
\hline $04 / 23 / 11$ & 0518-0519 & Twilight & $0527 / 1829$ & 72 \\
\hline $06 / 23 / 11$ & 0527 & Day & $0504 / 1859$ & \\
\hline $07 / 21 / 11$ & $1836-1839$ & Day & $0516 / 1856$ & \\
\hline $07 / 24 / 11$ & 1538 & Day & $0517 / 1854$ & \\
\hline $07 / 31 / 11$ & 1839 & Day & $0521 / 1850$ & \\
\hline 08/01/11 & $0520-0541$ & Twilight $\rightarrow$ day & $0522 / 1850$ & 0 , below horizon \\
\hline $08 / 25 / 11$ & $1711-1728$ & Day & $0534 / 1829$ & \\
\hline $08 / 28 / 11$ & $1711-1752$ & Day & $0536 / 1825$ & \\
\hline $08 / 29 / 11$ & $0538-0550$ & Day & $0536 / 1824$ & \\
\hline $09 / 15 / 11$ & 0259-0300 & Night & $0544 / 1805$ & 95 \\
\hline 09/15/11 & $0605-0607$ & Day & $0544 / 1805$ & \\
\hline $09 / 21 / 11$ & 1829 & Night & $0547 / 1758$ & 0 , below horizon \\
\hline $09 / 22 / 11$ & $0812-0854$ & Day & $0547 / 1757$ & \\
\hline $09 / 27 / 11$ & 0437 & Night & $0550 / 1751$ & 0 , below horizon \\
\hline $10 / 07 / 11$ & 0746 & Day & $0555 / 1740$ & \\
\hline $10 / 07 / 11$ & $1632-1715$ & Day & $0555 / 1740$ & \\
\hline $10 / 08 / 11$ & $0535-0536$ & Twilight & $0555 / 1738$ & 0 , below horizon \\
\hline $10 / 10 / 11$ & 0558 & Day & $0557 / 1736$ & \\
\hline $10 / 10 / 11$ & $1701-1723$ & Day & $0557 / 1736$ & \\
\hline $10 / 11 / 11$ & 0529-0559 & Night $\rightarrow$ twilight $\rightarrow$ day & $0557 / 1735$ & 0 , below horizon \\
\hline $10 / 12 / 11$ & $0541-0602$ & Twilight $\rightarrow$ day & $0558 / 1734$ & 100 \\
\hline $10 / 13 / 11$ & 1905 & Night & $0558 / 1733$ & 98 \\
\hline $10 / 14 / 11$ & 1933 & Night & $0559 / 1732$ & 95 \\
\hline
\end{tabular}

${ }^{a}$ Data obtained from Astronomical Applications Department of the United States Naval Observatory (USNO). http://aa.usno.navy.mil. Moon fraction refers to the moon's visible disk illuminated at the time the monkeys were active during twilight or at night

of events recorded, this or a nearby location was likely a nighttime sleeping site frequently used by $R$. brelichi.

Of all the camera trap images, the most noteworthy and unexpected ones were captured on September 15 when $R$. brelichi individuals were observed to be active at 0259-0300 hours. Although only nine images were taken, they showed several monkeys, possibly members of a reproductive unit, moving at a steady pace along a fixed route in a manner similar to behaviors exhibited during daytime periods (Fig. 1).

\section{Discussion}

The diel activity pattern of most living primates is characterized as either diurnal or nocturnal (Curtis and Rasmussen 2006). Since categorically diurnal and nocturnal primates differ significantly in their features of the visual system (Kay and Kirk 2000; Kirk and Kay 2004), this distinction has led to the assumption that primates are largely confined to a diel activity pattern due to constraints associated with a particular type of visual system. Among anthropoids, only members of the genus Aotus are known to be nocturnal (Wright 1989; Fernández-Duque 2003). Although nighttime activities of diurnal anthropoids have been alluded to in various accounts, in the absence of wellsubstantiated data, it is thought that these observations were anecdotal and diurnal primates normally remain inactive throughout the night (see review by Ankel-Simons and Rasmussen 2008). However, given that in nature primates experience varying intensity of illuminance throughout the 24-h day (Pariente 1980), a broad spectrum of visual capacity and behavioral flexibility would be expected and must not be overlooked (Ankel-Simons and Rasmussen 2008).

$R$. brelichi, according to conventional views, is believed to be exclusively diurnal. Overall our results concur with those obtained through direct observational studies that indicate $R$. brelichi, as other Chinese Rhinopithecus species, exhibits a predominantly diurnal activity pattern (e.g., Yang et al. 2002; Li 2009; Li et al. 2010; Xiang et al. 2010). However, our camera trap images provided 
irrefutable evidence that $R$. brelichi individuals are habitually active during twilight and night periods. We suspect that this extension of diurnal activity may reflect the species' behavioral adaptations to living in a temperate environment where day length and food resources are highly variable across seasons. It has been shown, for example in baboons, that seasonal variation in daylight hours may pose an ecological constraint on the time available for a diurnal species to perform vital daily activities (Dunbar 1988; Hill et al. 2003). Thus, having an adjustable activity schedule may confer sizable advantages by allowing $R$. brelichi to increase foraging effort during favorable conditions, and thereby enhance their energy reserves as a buffer against adverse conditions later. We believe flexibility in their diel activity pattern, as well as diet (Niu et al. unpubl. data), may enable $R$. brelichi to survive the harsh winter conditions in Fanjingshan.

Furthermore, the ability of $R$. brelichi to extend activity into twilight and nighttime periods may be linked to other adaptive features of the monkey's biology such as its visual system. It has been suggested that in mammals the visual system is shaped by the light regimes of the habitat in which each species lives (Veilleux and Lewis 2011). Thus, the visual system of $R$. brelichi may be optimized for functioning at low light (mesopic) levels as an adaptation to the forest of Fanjingshan where dense fog and low clouds are constant, resulting in a reduced light environment year-round. Indeed, there is much to be learned about the visual capabilities of $R$. brelichi and other Rhinopithecus species, and how their ecology has played a role in the evolution of their visual system or vice versa.

The observed diel activity pattern, derived from close to 300 days of 24-h continuous monitoring, was consistent throughout the study. As such, we believe this pattern may be the norm for $R$. brelichi. That $R$. brelichi (and possibly other temperate-dwelling Rhinopithecus species) exhibits a considerable amount of activity outside the typical diurnal observation schedule of researchers calls attention to methodological issues that arise from sampling bias. Granted that complete, full-day follows of free-ranging snub-nosed monkeys are labor intensive and difficult to achieve, we urge researchers to improve observational protocols and to reexamine the way in which we have characterized aspects of the monkeys' behavior (e.g., activity pattern, time budget, diet, ranging, sleeping site use) that were predicated upon incomplete sampling days and/or unequal sampling effort.

To facilitate cross-site and/or cross-species comparisons, we recommend that researchers adopt a standard definition for day length to determine activity patterns and time budgets. Also researchers should convert all local times to a meridian-based time calculated using the latitude and longitude coordinates of their study site when evaluating activity patterns in relation to rise and set of the sun (as explained in our "Methods").
Particularly, adjustments of local times are paramount for studies conducted in mainland China, where only one official time zone (CST) is maintained even though the country occupies five time zones by breadth of longitude. Activity data collected based on CST without corrections, when related to the timing of astronomical events at the research location, can produce grossly inaccurate and noncomparable results. As an example, Xiang et al. (2010) reported absolute time budgets of $R$. bieti in Tibet based on calculations of day length that included periods of nautical twilight (i.e., the sun at $6-12^{\circ}$ below the horizon; day length range $12-16 \mathrm{~h}$ ). However, their observations of the monkeys were limited to "dawn to dusk" periods on days only with acceptable weather conditions (Xiang et al. 2010, p 653). Assuming their definition of "dawn to dusk" observation was from sunrise to sunset, their absolute time budgets for $R$. bieti would be artificially inflated by about $10 \%$, an amount equal to the two daily periods of nautical twilight during which no observations were made.

In short, using camera traps we discovered extended periods of diel activity of $R$. brelichi that were previously undetected through direct observation. We consider camera traps a valuable scientific tool for primate research, particularly for studies of diel activity patterns, because these devices offer 24-h continuous monitoring with minimal disturbance to the animals. With regular equipment maintenance and proper sampling protocols, camera traps can simultaneously record year-round data on the study species and other animals in the community. Although direct observation is essential in providing contextual information regarding the animal's behavior, a remote camera-trapping approach certainly broadens not only our understanding of primate behavioral ecology, but also stimulates discussion about the need to further refine our observational study designs to reduce sampling bias.

Acknowledgments We thank W. Z. Huang, X. G. Yang, W. F. Huang, and X. M. Yang for assistance in the field and L. Shi, Y. Qiu, J. Jin, Y. Zeng, C. Yang, M. Liu, X. Lei, D. Sun, and W. Zhang at Fanjingshan National Nature Reserve for logistical support. A. Phillips, M. LaFleur, and an anonymous reviewer provided excellent comments on earlier drafts of this manuscript. Our research was supported by the Margot Marsh Biodiversity Foundation, the Offield Family Foundation, the Ocelots Grant, San Diego Zoo Global, Fanjingshan National Nature Reserve Administration, and the Forestry Department of Guizhou Province.

Open Access This article is distributed under the terms of the Creative Commons Attribution License which permits any use, distribution, and reproduction in any medium, provided the original author(s) and the source are credited.

\section{References}

Ankel-Simons F, Rasmussen DT (2008) Diurnality, nocturnality, and the evolution of primate visual systems. Yearb Phys Anthropol $51: 100-117$ 
Blake JG, Guerra J, Mosquera D, Torres R, Loiselle BA, Romo D (2010) Use of mineral licks by white-bellied spider monkeys (Ateles belzebuth) and red howler monkeys (Alouatta seniculus) in eastern Ecuador. Int J Primatol 31:471-483

Bleisch WV, Xie JH (1998) Ecology and behavior of the Guizhou snub-nosed langur (Rhinopithecus [Rhinopithecus] brelichi), with a discussion of socioecology in the genus. In: Jablonski NG (ed) The natural history of the doucs and snub-nosed monkeys. World Scientific, Singapore, pp 217-239

Bridges AS, Noss AJ (2011) Behavior and activity patterns. In: O'Connell AF, Nichols JD, Karanth KU (eds) Camera traps in animal ecology: methods and analyses. Springer, Tokyo, pp 57-69

Curtis DJ, Rasmussen MA (2006) The evolution of cathemerality in primates and other mammals: a comparative and chronoecological approach. Folia Primatol (Basel) 77:178-193

Dunbar RIM (1988) Primate social systems. Cornell University Press, Ithaca

Fernández-Duque E (2003) Influences of moonlight, ambient temperature, and food availability on the diurnal and nocturnal activity of owl monkeys (Aotus azarai). Behav Ecol Sociobiol 54:431-440

Grueter CC, Li DY, van Schaik CP, Ren BP, Long YC, Wei FW (2008) Ranging of Rhinopithecus bieti in the Samage forest China. I. Characteristics of range use. Int J Primatol 29:1121-1145

Hill RA, Barrett L, Gaynor D, Weingrill T, Dixon P, Payne H, Henzi SP (2003) Day length, latitude and behavioural (in) flexibility in baboons (Papio cynocephalus ursinus). Behav Ecol Sociobiol 53:278-286

Kay RF, Kirk EC (2000) Osteological evidence for the evolution of activity pattern and visual acuity in primates. Am J Phys Anthropol 113:235-262

Kays RW, Slauson KM (2008) Remote cameras. In: Long RA, MacKay P, Zielinski WJ, Ray JC (eds) Noninvasive survey methods for carnivores. Island, Washington, DC, pp 110-140

Kirk EC, Kay RF (2004) The evolution of high visual acuity in the Anthropoidea. In: Ross CF, Kay RF (eds) Anthropoid origins: new visions. Kluwer Academic/Plenum, New York, pp 539-602

Kirkpatrick RC, Long YC, Zhong T, Xiao L (1998) Social organization and range use in the Yunnan snub-nosed monkey Rhinopithecus bieti. Int J Primatol 19:13-51
Li Y (2009) Activity budgets in a group of Sichuan snub-nosed monkeys in Shennongjia Nature Reserve, China. Curr Zool (formerly Acta Zool Sin) 55:173-179

Li D, Ren B, Grueter CC, Li B, Li M (2010) Nocturnal sleeping habits of the Yunnan snub-nosed monkey in Xiangguqing, China. Am J Primatol 72:1092-1099

Niu K, Tan CL, Yang Y (2010) Altitudinal movements of Guizhou snub-nosed monkeys (Rhinopithecus brelichi) in Fanjingshan National Nature Reserve, China: implications for conservation management of a flagship species. Folia Primatol (Basel) $81: 233-244$

O'Brien TG, Kinnaird MF, Wibisono HT (2003) Crouching tigers, hidden prey: Sumatran tiger and prey populations in a tropical forest landscape. Anim Conserv 6:131-139

O'Connell AF, Nichols JD, Karanth KU (2011) Camera traps in animal ecology: methods and analyses. Springer, Tokyo

Pariente GF (1980) Quantitative and qualitative study of the light available in the natural biotope of Malagasy prosimians. In: Charles-Dominique P, Cooper HM, Hladik A, Hladik CM, Pages E, Pariente GF, Petter-Rousseux A, Schilling A (eds) Nocturnal Malagasy primates: ecology, physiology and behavior. Academic, New York, pp 117-134

Pebsworth PA, Bardi M, Huffman MA (2011) Geophagy in chacma baboons: patterns of soil consumption by age class, sex, and reproductive state. Am J Primatol 73:1-10

Tan CL, Guo ST, Li BG (2007) Population structure and ranging patterns of Sichuan snub-nosed monkeys (Rhinopithecus roxellana) in Zhouzhi National Nature Reserve, Shaanxi, China. Int J Primatol 28:577-591

Veilleux CC, Lewis RJ (2011) Effects of habitat light intensity on mammalian eye shape. Anat Rec 294:905-914

Wright PC (1989) The nocturnal primate niche in the New World. J Hum Evol 18:635-658

Xiang Z, Huo S, Xiao W (2010) Activity budget of Rhinopithecus bieti at Tibet: effects of day length, temperature and food availability. Curr Zool (formerly Acta Zool Sin) 56:650-659

Yang Y, Lei X, Yang C (2002) Fanjingshan research: ecology of the wild Guizhou snub-nosed monkey. Guizhou Science, Guiyang 